\title{
A push-pull system to reduce house entry of malaria mosquitoes
}

\author{
David J Menger ${ }^{1 *}$, Bruno Otieno², Marjolein de Rijk¹, W Richard Mukabana2,3, Joop JA van Loon \\ and Willem Takken ${ }^{1}$
}

\begin{abstract}
Background: Mosquitoes are the dominant vectors of pathogens that cause infectious diseases such as malaria, dengue, yellow fever and filariasis. Current vector control strategies often rely on the use of pyrethroids against which mosquitoes are increasingly developing resistance. Here, a push-pull system is presented, that operates by the simultaneous use of repellent and attractive volatile odorants.

Method/Results: Experiments were carried out in a semi-field set-up: a traditional house which was constructed inside a screenhouse. The release of different repellent compounds, para-menthane-3,8-diol (PMD), catnip oil e.o. and delta-undecalactone, from the four corners of the house resulted in significant reductions of $45 \%$ to $81.5 \%$ in house entry of host-seeking malaria mosquitoes. The highest reductions in house entry (up to 95.5\%), were achieved by simultaneously repelling mosquitoes from the house (push) and removing them from the experimental set-up using attractant-baited traps (pull).

Conclusions: The outcome of this study suggests that a push-pull system based on attractive and repellent volatiles may successfully be employed to target mosquito vectors of human disease. Reductions in house entry of malaria vectors, of the magnitude that was achieved in these experiments, would likely affect malaria transmission. The repellents used are non-toxic and can be used safely in a human environment. Delta-undecalactone is a novel repellent that showed higher effectiveness than the established repellent PMD. These results encourage further development of the system for practical implementation in the field.
\end{abstract}

Keywords: Mosquitoes, Malaria, Vector control, Repellent, Push-pull

\section{Background}

Mosquitoes are the dominant vectors of pathogens that cause infectious diseases such as malaria, dengue, yellow fever and filariasis [1,2]. Vector control strategies are aimed at disrupting transmission cycles and are an important tool in the prevention of these diseases. Current vector control strategies often rely on the use of insecticide-treated nets (ITNs) and indoor residual spraying (IRS) [3,4]. However, the rapidly increasing resistance of mosquitoes to the active chemicals on which these strategies depend implies a serious limitation of their efficacy [5-8].

The literature provides examples of various alternative vector control tools that could be employed as supplements to, or possibly even as replacements of, ITNs and IRS

\footnotetext{
* Correspondence: david.menger@wur.nl

'Laboratory of Entomology, Wageningen University, P.O. Box 8031, 6700, EH Wageningen, The Netherlands

Full list of author information is available at the end of the article
}

(reviewed by [9]). A tool which has previously proven its value in the context of agricultural pest management is the so called 'push-pull system' [10]. A push-pull system manipulates the behaviour and/or distribution of pest insects by the simultaneous use of repellent and attractive stimuli. In this paper, a push-pull system is introduced, that is directed at the major African malaria vector Anopheles gambiae sensu stricto (s.s.). The system is based on removal trapping and the release of spatial repellents.

Removal trapping is a strategy that aims at reducing the target insect population with attractive traps placed in strategic locations. This strategy is effective against tsetse flies (Glossina spp.), which transmit trypanosomiasis (sleeping sickness), and against other disease vectors [11]. Recent laboratory and field experiments have led to the development of odour blends based on ammonia, L-lactic acid and carboxylic acids which, in combination with carbon dioxide $\left(\mathrm{CO}_{2}\right)$, can be used as baits 
to effectively trap tropical mosquitoes, including malaria vectors [12-18].

Repellents can be applied topically for personal protection, e.g. the widely used insect repellent DEET (N,N-diethylmeta-toluamide), but can also be dispersed spatially to protect a space, e.g. the burning of repellent-impregnated coils, candles that contain certain essential oils or leaves of specific tree species [19-22]. Repellents that exhibit a spatial effect may be considered for inclusion in a pushpull system.

The use of push-pull tactics fits within the emerging view that vector control strategies should be expanded beyond insecticide-dependent methods [4]. Combining the mechanisms of attraction and repellency has the potential to result in a synergistic effect [10]. By 'pushing' mosquitoes away from certain places using repellents, one could stimulate their movement towards other places where they are 'pulled' into traps baited with attractive cues. Now that highly attractive synthetic odour blends that mimic human scent are at the disposal of the scientific community, the remaining challenge lies in the development or selection of effective spatial repellents directed at the target group.

In this paper, two experiments are presented in which it is demonstrated how (1) a push-pull system was employed in a semi-field situation where it successfully reduced house entry of the predominant malaria vector in sub-Saharan Africa, An. gambiae s.s. and (2) this push-pull system was improved with the introduction of a novel mosquito repellent that displays a superior spatial effect.

\section{Methods}

\section{Mosquitoes}

The mosquitoes (An. gambiae s.s., Mbita strain; henceforth termed An. gambiae) were reared under ambient atmospheric conditions in screenhouses (larvae) and indoors (adults) at the Thomas Odhiambo Campus (TOC) of the International Centre of Insect Physiology and Ecology (icipe) located near Mbita Point township in western Kenya. Mosquito eggs were placed in plastic trays containing filtered water from Lake Victoria. All larval instars were fed on Tetramin ${ }^{\circ}$ baby fish food which was supplied thrice per day. Pupae were collected daily and placed in meshcovered cages $(30 \times 30 \times 30 \mathrm{~cm})$ prior to adult emergence. Adult mosquitoes were fed on $6 \%$ glucose solution through wicks made from adsorbent tissue paper.

Female mosquitoes of $3-6$ days old since eclosion that had no prior access to blood were used for the semi-field experiments. The mosquitoes were collected from the colony at 12:00 h each day and stored for $8 \mathrm{~h}$ in the colony room with access to water on cotton wool. Within 15 min before the start of the experiment the cups with the mosquitoes were transported to the experimental set-up.

\section{Description of the set-up}

The experiments were conducted at the Mbita Point Research \& Training Centre of icipe in Kenya. Experiments took place in the MalariaSphere (Figure 1), a screenhouse into which a traditional house was built surrounded by natural vegetation [23]. The traditional house possesses an eave, through which mosquitoes that are released into the screenhouse may enter, as they would do in a natural situation when an attractive host is present inside [24]. The MalariaSphere was set up as described [23], with the only modification that no breeding sites were present.

\section{Experimental design}

Both experiments explored the effects of attractant-baited traps and the dispersal of repellents around the traditional house. Four different set-ups were tested during experiment 1 and eight different set-ups were tested during experiment 2. During all tests, one attractant-baited trap (see below) was placed inside the experimental house to represent a human being. The house entry of the mosquitoes was measured by the number of mosquitoes caught by the trap inside the house.

Each night at 20:00 h, 200 female mosquitoes were released into the MalariaSphere. At 6:30 h the next morning the experiment was terminated by closing and switching off the ventilators of all traps. The traps were then placed in a freezer for several minutes to inactivate the mosquitoes, after which the numbers of trapped mosquitoes were determined.

\section{Experiment 1}

The four set-ups that were tested during experiment 1 included: (1) a control set-up in which only the attractive trap inside the house was present, (2) a push-only situation in which a repellent was released from the four corners of the house, (3) a pull-only situation in which four attractant baited-traps were positioned around the house and (4) a situation in which the total push-pull system was set up with both the repellent and the attractant components in place. See Table 1 for the presence/ absence of the specific traps during the treatments and Figure 2 for an overview of their positions. Each set-up was tested during eight different nights, thus a total of 32 tests was carried out during the same number of nights. The order of the tests was not fully randomized in order to minimize the risk of contamination of the MalariaSphere with the used odours. The repellent compound selected for this experiment was para-menthane3,8-diol (PMD) [25]. Nylon strips were impregnated with a $40 \%$ solution of commercially available Citriodiol $^{\mathrm{TM}}$ (containing $>64 \%$ PMD) as described below. At the start of each test, the mosquitoes were released from four different spots around the house (50 mosquitoes per spot), see Figure 2. 


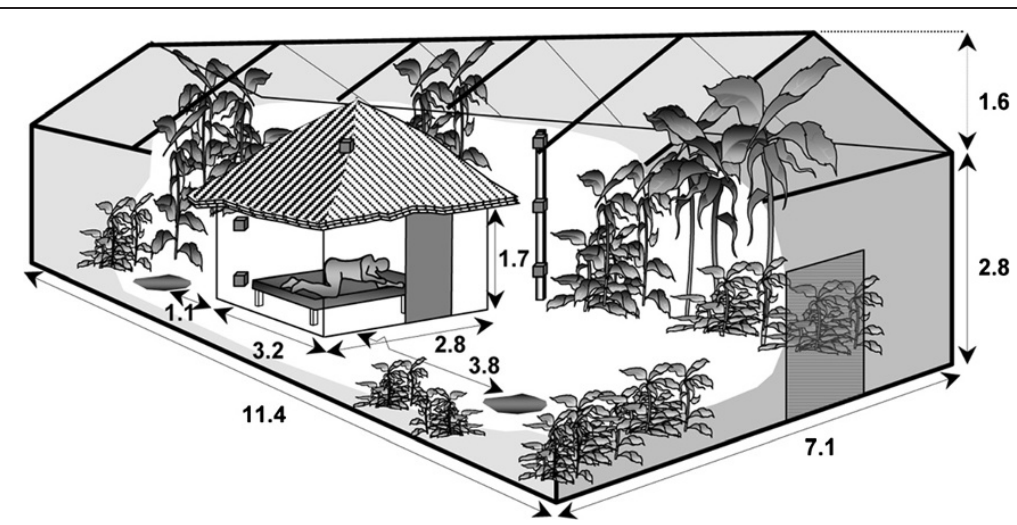

Figure 1 The MalariaSphere; a screenhouse with a traditional house constructed inside (image copied from [23]).

\section{Experiment 2}

During experiment 2, eight different set-ups were tested. This study compared the effect of three different repellents in push-only situations as well as in situations in which both a repellent and the attractive blend were released; see Table 2 and Figure 3 for a comprehensive overview of which repellent compound was used during the different tests, the presence/absence of the repellent and attractive components and their positions. Each set-up was tested during six different nights, thus a total of 48 tests was carried out, during the same number of nights. The order of the tests was not fully randomized in order to minimize the risk of contamination of the MalariaSphere with the used odours. PMD (see Experiment 1), catnip essential oil (e.o.) $[26,27]$ and delta-undecalactone (dUDL; patent pending) [28] were used as repellents. Strips were impregnated with $40 \%$ solutions (catnip e.o. and dUDL were dissolved in paraffin oil) as described below. During Experiment 2, all 200 mosquitoes were released from one central point between the entrance of the screenhouse and the experimental hut (see Figure 3).

\section{Attractant-baited traps}

Mosquito Magnet ${ }^{\bullet}$ X (MM-X) traps [29,30] were baited with $\mathrm{CO}_{2}$ and a five-compound odour blend, which simulates the smell of a human foot $[18,28]$. The individual compounds of the attractive blend were released from nylon strips (cut from panty hoses: $90 \%$ polyamide,

Table 1 Placement of attractants and repellents in experiment 1 (Yes/No)

\begin{tabular}{cccc}
\hline Treatment & Attractant inside & Attractant outside & Repellent outside \\
\hline 1 & $\mathrm{Y}$ & $\mathrm{N}$ & $\mathrm{N}$ \\
2 & $\mathrm{Y}$ & $\mathrm{N}$ & $\mathrm{Y}$ \\
3 & $\mathrm{Y}$ & $\mathrm{Y}$ & $\mathrm{N}$ \\
4 & $\mathrm{Y}$ & $\mathrm{Y}$ & $\mathrm{Y}$ \\
\hline
\end{tabular}

See also Figure 2.
10\% spandex, Marie Claire ${ }^{\odot}$ [31]. Concentrations were optimised for this set-up and release method: ammonia (2.5\% in water), L-(+)-lactic-acid (85\%), tetradecanoic acid $(0.00025 \mathrm{~g} / \mathrm{l}$ in ethanol), 3-methyl-1-butanol $(0.000001 \%$ in water $)$ and butan-1-amine $(0.001 \%$ in paraffin oil) (see Table 3$)$. Nylon strips $(26.5 \mathrm{~cm} \times 1 \mathrm{~cm})$ were impregnated with the attractive compounds by dipping three strips in $3.0 \mathrm{ml}$ of compound in a $4 \mathrm{ml} \mathrm{screw}$ top vial (Experiment 1) or by dipping individual strips into an Eppendorf tube containing $1 \mathrm{ml}$ of solution (Experiment 2). Before use, strips were dried for 9-10 $\mathrm{h}$ at room temperature. During experiment 1 for every experimental night a set of freshly impregnated strips was used. During

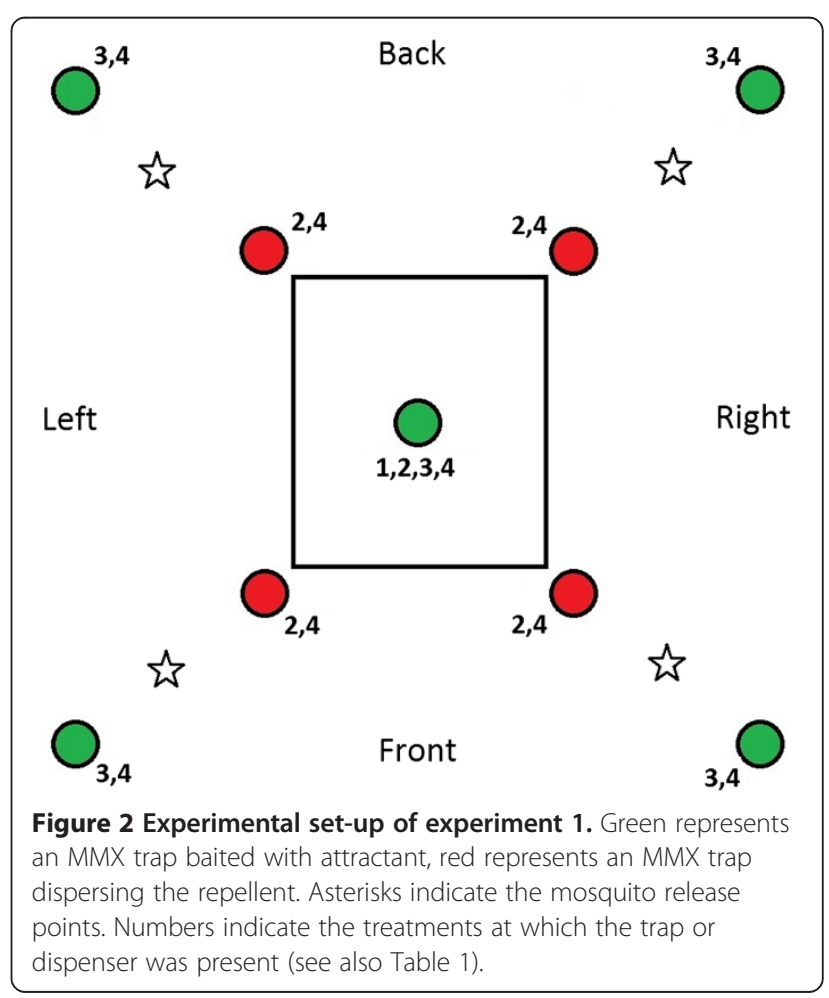


Table 2 Placement of attractants and repellents in experiment 2 (Yes/No)

\begin{tabular}{cccc}
\hline Treatment & Attractant inside & Attractant outside & Repellent outside \\
\hline 1 & $Y$ & $N$ & $N$ \\
2 & $Y$ & $N$ & $Y(P M D)$ \\
3 & $Y$ & $N$ & $Y($ Catnip) \\
4 & $Y$ & $N$ & $Y(d U D L)$ \\
5 & $Y$ & $Y$ & $N$ \\
6 & $Y$ & $Y$ & $Y(P M D)$ \\
7 & $Y$ & $Y$ & $Y($ Catnip) \\
8 & $Y$ & $Y$ & $Y(d U D L)$ \\
\hline
\end{tabular}

See also Figure 3.

experiment 2 strips were used for a maximum of 12 consecutive nights. During daytime, the strips were packed in aluminium foil and stored at $4^{\circ} \mathrm{C}$ in a refrigerator.

The five strips were held together with a safety pin and hung in the outflow opening of the MM-X trap using a plastic covered clip. $\mathrm{CO}_{2}$ was produced by mixing $17.5 \mathrm{~g}$ yeast with $250 \mathrm{~g}$ sugar and $2.5 \mathrm{~L}$ water [32] and released from the MM-X trap together with the odours. MM-X traps equipped with the attractive blend were positioned with the outflow opening at the optimal height of $15-20 \mathrm{~cm}$ above the floor surface [33].

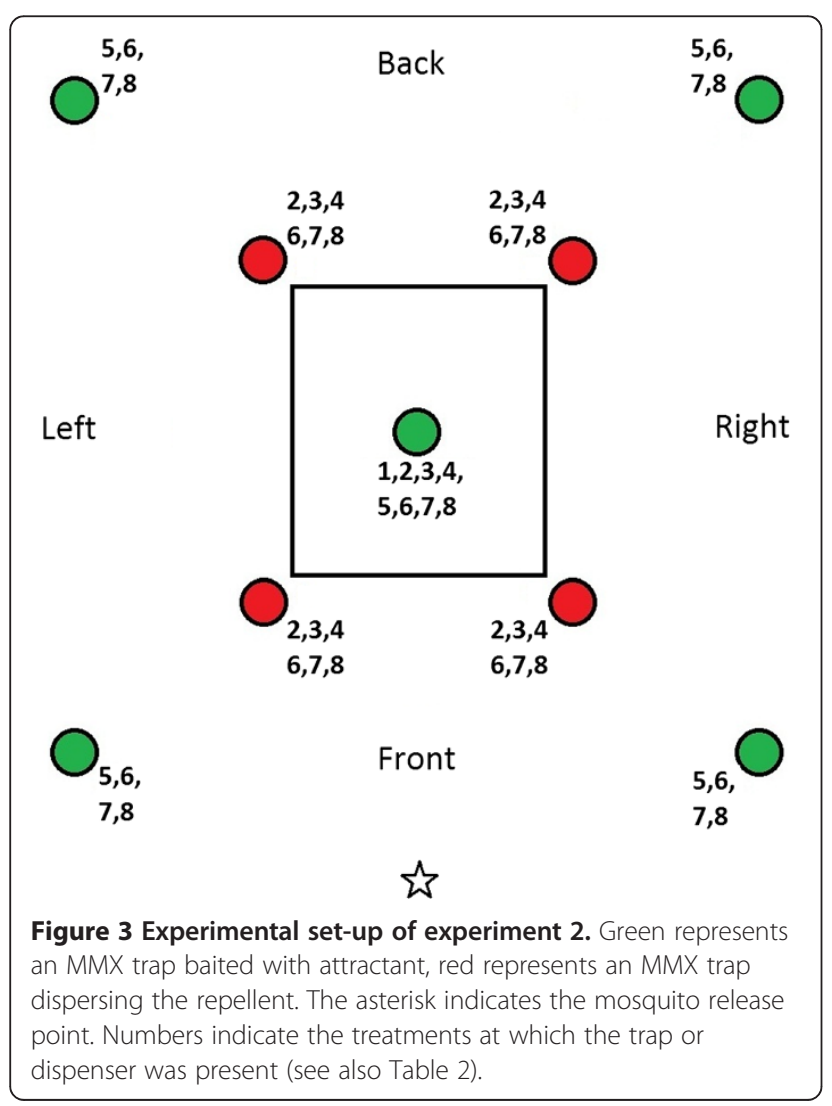

Table 3 Composition of the attractive blend

\begin{tabular}{lrr}
\hline Compound & Concentration & Solvent \\
\hline Ammonia & $2.5 \%(\mathrm{v} / \mathrm{v})$ & Water \\
L-(+)-lactic acid & $85 \%(\mathrm{w} / \mathrm{W})$ & Water \\
Tetradecanoic acid & $0.00025 \mathrm{~g} / \mathrm{l}$ & Ethanol \\
3-Methyl-1-butanol & $0.000001 \%(\mathrm{v} / \mathrm{v})$ & Water \\
Butan-1-amine & $0.001 \%(\mathrm{v} / \mathrm{v})$ & Paraffin oil \\
\hline
\end{tabular}

\section{Dispersal of the repellents}

To disperse the repellents, MM-X traps were used of which the suction mechanism was disabled; leaving only the outflow mechanism functional [15]. The repellent compounds were applied to nylon strips identically to the attractants. However, because of their volatility the strips with repellent were dried for only $1 \mathrm{~h}$ (Experiment 1 ) or $10 \mathrm{~min}$ (Experiment 2). One repellent strip was used per MM-X trap. Freshly prepared strips were used each night. The MM-X traps that dispersed the repellent were hung from the lowest part of the roof of the traditional house, with the outflow opening about $1 \mathrm{~m}$ above the floor, to intercept mosquitoes that would enter through the eaves of the experimental hut.

\section{Statistical analysis}

For both experiments, the trap catches inside and (when applicable) outside the experimental house were compared between all treatments. The Shapiro-Wilk test was used to test the normality of the data and Levene's test was used to test for equality of variances. Subsequently, the differences between trap catches inside the house in Experiment 1 were analysed using analysis of variance (ANOVA) followed by Bonferroni post-hoc tests. Trap catches outside were compared using an independentsamples t-test. Differences between trap catches inside the house in Experiment 2 were analysed using ANOVA followed by Games-Howell post-hoc tests. Trap catches outside the house were compared using ANOVA followed by Bonferroni post-hoc tests.

\section{Results}

\section{Experiment 1}

During the control tests, the attractant-baited trap inside the house caught on average 62.0 (SEM 8.7) or 31.0\% of the released mosquitoes. The release of PMD (push only), removal trapping (pull only) and the combination of both strategies (push-pull) all significantly reduced the house entry of $A n$. gambiae compared to the control situation (ANOVA: $\mathrm{F}=21.53, \mathrm{df}=3, \mathrm{p}<0.001$; Bonferroni post-hoc tests at $\alpha=0.05$, see Figure 4 ).

When PMD was released from the four corners of the house, the number of trapped mosquitoes dropped to 31.1 (8.2); a reduction of nearly $50 \%$. With four attractant-baited traps placed around the house, even fewer mosquitoes 


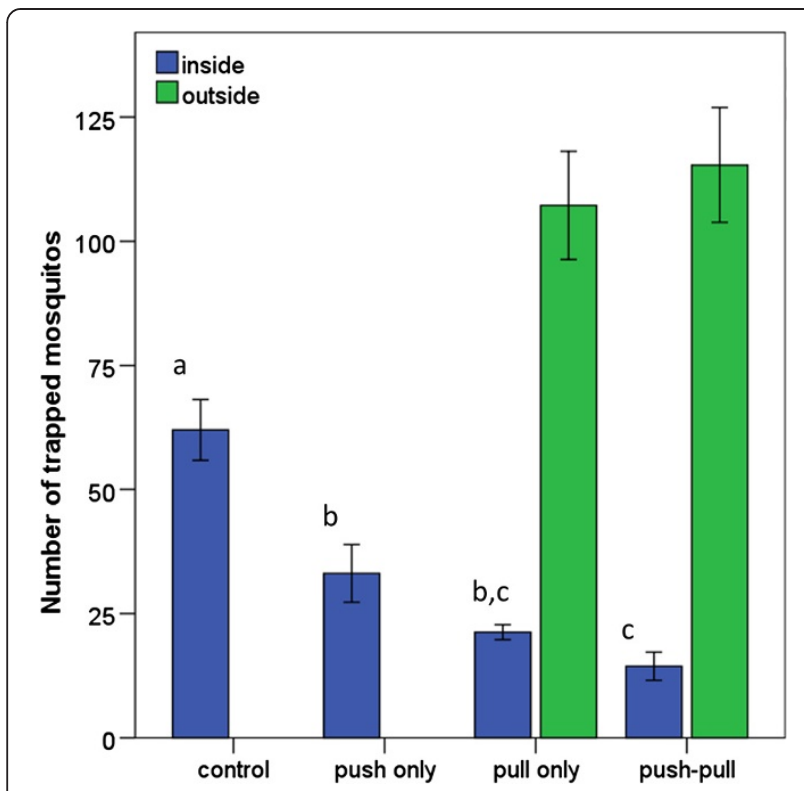

Figure 4 Mean number of mosquitoes trapped inside and, when applicable, outside the experimental house. For all treatments $n=8$, error bars indicate the standard error of the mean. Bars not sharing the same character are significantly different at $a=0.05$ with Bonferroni post-hoc tests.

entered the house, with the trap indoors catching only 21.3 (2.1) mosquitoes on average. The four traps outdoors caught 107.3 (15.4) mosquitoes or $53.7 \%$ of the total number released. With both the push and the pull components in place, the number of mosquitoes trapped indoors was lowest, with only 14.4 (4.0) mosquitoes on average, or $7.2 \%$ of the total number released. This implies a reduction of more than $75 \%$ compared to the control treatment. The traps outdoors caught an average of 115.4 (16.3) mosquitoes in the push-pull scenario.

\section{Experiment 2}

In the absence of repellent dispensers or removal trapping, the attractant-baited trap inside the house caught 82.0 (4.0) mosquitoes on average; $41.0 \%$ of the total number released. As in the previous experiment, all treatments significantly reduced the number of mosquitoes trapped in the experimental house (ANOVA: $\mathrm{F}=70.08$, $\mathrm{df}=7, \mathrm{p}<0.001$; Games-Howell post-hoc tests at $\alpha=0.05$, see Figure 5).

The push-only treatment in which delta-undecalactone was dispensed caused a significantly stronger reduction (81.5\%) than the treatments with PMD or catnip e.o ( $45.7 \%$ and $56.5 \%$ resp.), of which catnip e.o. performed slightly (ns) better. Removal trapping (pull only) led to a 82.3\% reduction, with the trap inside the house catching only 14.5 (2.0) mosquitoes on average. The push-pull treatment employing delta-undecalactone as a repellent provided the strongest reduction, $95.5 \%$; only $3.7(0.7)$ mosquitoes were caught inside the house on average; $1.9 \%$ of the total number released. The total number of mosquitoes trapped outdoors did not differ significantly between the treatments that included removal trapping.

\section{Discussion}

Efficacy of the push-pull system

An attractant-baited trap placed inside a traditional house caught $31 \%$ (experiment 1) to $41 \%$ (experiment 2) of the mosquitoes released in the screenhouse. Therefore, hostseeking female mosquitoes must have entered the house attracted by the combination of odour $+\mathrm{CO}_{2}$ that was deployed to mimic a potential host. This confirms that the odour blend $+\mathrm{CO}_{2}$ functions analogous to a human host in terms of inducing house entry as a component of host-seeking behaviour $[15,18]$.

The release of PMD from the four corners of the house resulted in a significant reduction of over $45 \%$ in house entry of host-seeking mosquitoes. Therefore, anyone being indoors would have received fewer mosquito bites under this treatment. Experiment 2 showed that this effect improved significantly (to $81.5 \%$ ) when PMD was replaced by delta-undecalactone.

The placement of attractant-baited traps around the house significantly reduced the number of mosquitoes trapped inside the house, in both experiments. Instead of entering the house, a high percentage $(53.7 \%$ and $44.1 \%$ resp.) was lured into the traps placed outdoors.

These examples show that it is feasible to trap or repel host-seeking mosquitoes before house entry, thereby rendering protection to the house occupants. The highest reductions in house entry (up to 95.5\%), and thus the highest degrees of protection, were achieved by simultaneously repelling mosquitoes from the house (push) and removing them from the experimental set-up by trapping (pull). Although outdoor trap catches were slightly elevated when both push and pull were present, compared to pull only, there was no statistical indication that a greater push led to a greater pull or vice versa. Rather than a synergistic interaction between both components, the attractant and repellent seem to have independent effects that, by their different modes of action, complement each other.

\section{Spatial repellency}

The results also show that PMD, catnip e.o. and deltaundecalactone, had an effect on the mosquitoes over a large distance, as the places from where the repellents were dispensed were approx. $3 \mathrm{~m}$ apart. Released in an appropriate way, in the present experiments by active dispersion from nylon fabric, these compounds thus act as spatial repellents.

PMD has previously been shown to be an effective repellent against mosquitoes of several genera, including 


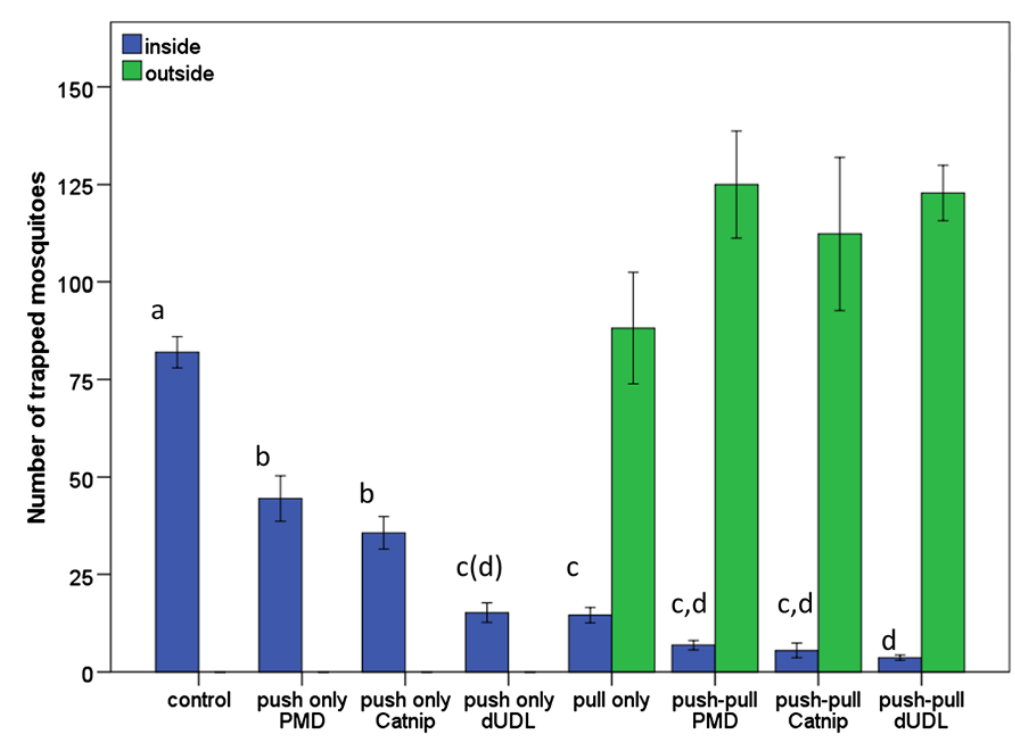

Figure 5 Mean number of mosquitoes trapped inside and, when applicable, outside the experimental house. For all treatments $n=6$, error bars indicate the standard error of the mean. Bars not sharing the same character are significantly different at $a=0.05$ with Games-Howell post-hoc tests. (d): $p=0.05081$ for the comparison between the push-only dUDL treatment and the push-pull dUDL treatment.

vectors of human disease ([25] and references therein). Catnip e.o. has also been reported as an insect repellent, with proven effect on mosquito species of several genera including Aedes, Anopheles and Culex [26,27,34,35].

Delta-undecalactone was first identified in studies of the olfactory receptors of An. gambiae using ex vivo heterologous olfactory receptor expression assays [36] and in vivo electrophysiological studies on antennal sensilla [37-39]. Subsequently, it was selected for tests in a repellent bioassay, where it showed an equal or higher level of repellency than DEET [28]. The superior spatial repellent effect it displayed in this experiment underlines its potential as a new repellent that may be used for the control of mosquito vectors of disease. Because delta-undecalactone is a natural product present in edible fruits and dairy products $[40,41]$, regulatory issues concerning its use as a repellent are expected to be limited making it a suitable compound for inclusion in vector-control programmes.

\section{Field implementation}

The outcome of this study suggests that a push-pull system based on odorant volatiles may successfully be employed to target mosquito vectors of human disease. Reductions in house-entry of the magnitude observed in this study, would likely affect malaria transmission, especially in areas where mosquito densities are low and malaria risk is directly related to the entomological inoculation risk [42]. So far, house entry reductions of this magnitude are only known for pyrethroid insecticides (e.g. $[43,44])$. The results presented here justify the decision to keep working on a field-proof push-pull system based on a combination of non-pyrethroid repellents and attractants.

The usefulness of push-pull systems for control of mosquito-borne diseases will not only depend on their efficacy in repelling and trapping mosquitoes, but also on their applicability and cost-effectiveness [45]. For malaria control, vector control measures should be affordable and usable in rural African settings. In its current shape, employing up to nine electrically-powered MM-X traps, the push-pull system presented here does not meet these requirements. Therefore, follow-up experiments are planned to further optimize this system and explore the practical implementation of an odour-based push-pull system that is less dependent on electric power.

Attractant odour baits have been reported that can be formulated to last for several months [46]. Odour-baited traps can be operated and maintained by house owners, preferably through a community approach, improving the sustainability of this vector control method. Studies on repellent formulation and passive distribution mechanisms are still required.

Finally, this system may also be considered in areas where most of malaria transmission occurs outdoors $[47,48]$, where it is expected to increase the efficacy of existing methods such as ITNs and IRS that do not target host-seeking mosquitoes outside the house.

\section{Conclusion}

This study shows a strong spatial effect of PMD, catnip oil and delta-undecalactone, when dispensed around a house in a semi-field set-up. Combined with an attractant in a push-pull strategy, the volatile repellents caused 
highly significant reductions in house entry of the major African malaria vector An. gambiae. These results encourage further development of the system for practical implementation in the field.

\section{Competing interests}

The authors declare that they have no competing interests.

\section{Authors' contributions}

$\mathrm{DM}, \mathrm{MdR}, \mathrm{RM}, \mathrm{JVL}$ and $\mathrm{WT}$ designed the experiments. DM, BO and MdR conducted the experiments. DM analysed the data. DM, JVL and WT wrote the manuscript. All authors read and approved the final manuscript.

\section{Acknowledgements}

The authors wish to thank the rearing staff at icipe Mbita for providing the mosquitoes used in this study. This study was funded by a grant from the Foundation for the National Institutes of Health through the Grand Challenges in Global Health Initiative (GCGH\#121).

\section{Author details}

'Laboratory of Entomology, Wageningen University, P.O. Box 8031, 6700, EH Wageningen, The Netherlands. ${ }^{2}$ International Centre of Insect Physiology and Ecology, P.O. Box 30772, GPO Nairobi, Kenya. ${ }^{3}$ School of Biological Sciences, University of Nairobi, P.O. Box 30197, 00100, GPO Nairobi, Kenya.

Received: 20 January 2014 Accepted: 23 March 2014

Published: 27 March 2014

\section{References}

1. Gratz NG: Emerging and resurging vector-borne diseases. Annu Rev Entomol 1999, 44:51-75.

2. WHO: WHO Fact sheets: Infectious diseases. Geneva: World Health Organization [http://www.who.int/topics/infectious_diseases/factsheets/en/index.html]

3. van den Berg $\mathrm{H}$, Takken W: Evaluation of integrated vector management. Trends Parasitol 2008, 25:71-76.

4. Thomas MB, Godfray HCJ, Read AF, van den Berg H, Tabashnik BE, van Lenteren JC, Waage JK, Takken W: Lessons from agriculture for the sustainable management of malaria vectors. PLoS Med 2012, 9:e1001262.

5. Ranson H, N'Guessan R, Lines J, Moiroux N, Nkuni Z, Corbel V: Pyrethroid resistance in African anopheline mosquitoes: what are the implications for malaria control? Trends Parasitol 2011, 27:91-98.

6. Kanza JPB, el Fahime E, Alaoui S, Essassi EM, Brooke B, Malafu AN, Tezzo FW: Pyrethroid, DDT and malathion resistance in the malaria vector Anopheles gambiae from the Democratic Republic of Congo. Trans R Soc Trop Med Hyg 2012, 107:8-14

7. Mawejje HD, Wilding CS, Rippon EJ, Hughes A, Weetman D, Donnelly MJ: Insecticide resistance monitoring of field-collected Anopheles gambiae s.l. populations from Jinja, eastern Uganda, identifies high levels of pyrethroid resistance. Med Vet Entomol 2012, 27:276-283.

8. Ochomo E, Bayo MN, Brogdon WG, Gimnig JE, Ouma C, Vulule JM, Walker ED: Pyrethroid resistance in Anopheles gambiae s.s. and Anopheles arabiensis in western Kenya: phenotypic, metabolic and target site characterizations of three populations. Med Vet Entomol 2012, 27:156-164.

9. Takken W, Knols BGJ: Malaria vector control: current and future strategies. Trends Parasitol 2009, 25:101-104.

10. Cook SM, Khan ZR, Pickett JA: The use of push-pull strategies in Integrated Pest Management. Annu Rev Entomol 2007, 52:375-400.

11. Day JF, Sjogren RD: Vector control by removal trapping. Am J Trop Med Hyg 1994, 50:126-133.

12. Braks MAH, Meijerink J, Takken W: The response of the malaria mosquito, Anopheles gambiae, to two components of human sweat, ammonia and lactic acid, in an olfactometer. Physiol Entomol 2001, 26:142-148.

13. Smallegange RC, Qiu YT, van Loon JJA, Takken W: Synergism between ammonia, lactic acid and carboxylic acids as kairomones in the host-seeking behaviour of the malaria mosquito Anopheles gambiae sensu stricto (Diptera: Culicidae). Chem Senses 2005, 30:145-152.

14. Smallegange RC, Qiu YT, Bukovinszkiné-Kiss G, van Loon JJA, Takken W: The effect of aliphatic carboxylic acids on olfaction-based host-seeking of the malaria mosquito Anopheles gambiae sensu stricto. J Chem Ecol 2009, 35:933-943.
15. Okumu FO, Killeen GF, Ogoma S, Biswaro L, Smallegange RC, Mbeyela E, Titus E, Munk C, Ngonyani H, Takken W, Mshinda H, Mukabana WR, Moore SJ: Development and field evaluation of a synthetic mosquito lure that is more attractive than humans. PLoS One 2010, 5:e8951.

16. Jawara M, Awolola TS, Pinder M, Jeffries D, Smallegange RC, Takken W, Conway DJ: Field testing of different chemical combinations as odour baits for trapping wild mosquitos in the Gambia. PLoS One 2011, 6:e19676.

17. Verhulst NO, Mbadi PA, Bukovinszkiné Kiss G, Mukabana WR, van Loon JJA, Takken W, Smallegange RC: Improvement of a synthetic lure for Anopheles gambiae using compounds produced by human skin microbiota. Malar J 2011, 10:28.

18. Mukabana WR, Mweresa CK, Otieno B, Omusula P, Smallegange RC, van Loon JJA, Takken W: A novel synthetic odorant blend for trapping of malaria and other African mosquito species. J Chem Ecol 2012, 38:235-244.

19. Lindsay LR, Surgeoner GA, Heal JD, Gallivan GJ: Evaluation of the efficacy of $3 \%$ citronella candles and $5 \%$ citronella incense for protection against field populations of Aedes mosquitoes. J Am Mosa Control Assoc 1996, 12:293-294

20. Seyoum A, Palsson K, Kung'a S, Kabiru EW, Lwande W, Killeen GF, Hassanali A, Knols BG: Traditional use of mosquito-repellent plants in western Kenya and their evaluation in semi-field experimental huts against Anopheles gambiae: ethnobotanical studies and application by thermal expulsion and direct burning. Trans R Soc Trop Med Hyg 2002, 96:225-231.

21. Alten B, Caglar SS, Simsek FM, Kaynas, Perich MJ: Field evaluation of an area repellent system (Thermacell) against Phlebotomus papatasi (Diptera: Psychodidae) and Ochlerotatus caspius (Diptera: Culicidae) in Sanliurfa Province, Turkey. J Med Entomol 2003, 40:930-934.

22. Dugassa S, Medhin G, Balkew M, Seyoum A, Gebre-Michael T: Field investigation on the repellent activity of some aromatic plants by traditional means against Anopheles arabiensis and An. pharoensis (Diptera: Culicidae) around Koka, central Ethiopia. Acta Trop 2009, 112:38-42.

23. Knols BGJ, Njiru BN, Mathenge EM, Mukabana WR, Beier JC, Killeen GF: MalariaSphere: A greenhouse-enclosed simulation of a natural Anopheles gambiae (Diptera: Culicidae) ecosystem in western Kenya. Malar J 2002, 1:19.

24. Snow WF: Studies of house-entering habits of mosquitoes in The Gambia, West Africa: experiments with prefabricated huts with varied wall apertures. Med Vet Entomol 1987, 1:9-21.

25. Carroll SP, Loye J: PMD, a registered botanical mosquito repellent with Deet-like efficacy. J Am Mosq Control Assoc 2006, 22:507-514.

26. Bernier UR, Furman KD, Kline DL, Allan SA, Barnard DR: Comparison of contact and spatial repellency of catnip oil and N, N-Diethyl-3-methylbenzamide (Deet) against mosquitoes. J Med Entomo 2005, 42:306-311.

27. Birkett MA, Hassanali A, Hoglund S, Pettersson J, Pickett JA: Repellent activity of catmint, Nepeta cataria, and iridoid nepetalactone isomers against Afro-tropical mosquitoes, ixodid ticks and red poultry mites. Phytochemistry 2011, 72:109-114.

28. Menger DJ, van Loon JJA, Takken W: Assessing the efficacy of candidate mosquito repellents against the background of an attractive source that mimics a human host. Med Vet Entomol. in press.

29. Njiru BN, Mukabana WR, Takken W, Knols BGJ: Trapping of the malaria vector Anopheles gambiae with odour-baited MM-X traps in semi-field conditions in western Kenya. Malar J 2006, 5:39.

30. Qiu YT, Smallegange RC, ter Braak CJF, Spitzen J, van Loon JJA, Jawara M, Milligan P, Galimard AM, van Beek TA, Knols BGJ, Takken W: Attractiveness of MM-X traps baited with human or synthetic odour to mosquitoes (Diptera: Culicidae) in The Gambia. J Med Entomol 2007, 44:970-983.

31. Okumu F, Biswaro L, Mbeleyela E, Killeen GF, Mukabana R, Moore SJ: Using nylon strips to dispense mosquito attractants for sampling the malaria vector Anopheles gambiae s.s. J Med Entomol 2010, 47:274-282.

32. Smallegange RC, Schmied WH, van Roey KJ, Verhulst NO, Spitzen J, Mukabana WR, Takken W: Sugar-fermenting yeast as an organic source of carbon dioxide to attract the malaria mosquito Anopheles gambiae. Malar J 2010, 9:292.

33. Jawara M, Smallegange RC, Jeffries D, Nwakanma DC, Awolola TS, Knols BGJ, Takken W, Conway DJ: Optimizing odor-baited trap methods for collecting mosquitoes during the malaria season in The Gambia. PLoS One 2009, 4:e8167.

34. Zhu J, Zeng X, Ma Y, Liu T, Qian K, Han Y, Xue S, Tucker B, Schultz G, Coats J, Rowley W, Zhang A: Adult repellency and larvicidal activity of five plant essential oils against mosquitoes. J Am Mosq Control Assoc 2006, 22:515-522.

35. Polsomboon S, Grieco JP, Achee NL, Chauhan KR, Tanasinchayakul S, Pothikasikorn J, Chareonviriyaphap T: Behavioral responses of catnip 
(Nepeta cataria) by two species of mosquitoes, Aedes aegypti and Anopheles harrisoni, in Thailand. J Am Mosa Control Assoc 2008, 24:513-519.

36. Wang GR, Carey AF, Carlson JR, Zwiebel L: Molecular basis of odor coding in the malaria vector mosquito Anopheles gambiae. Proc Natl Acad Sci USA 2010, 107:4418-4423.

37. Qiu YT, van Loon JJA, Takken W, Meijerink J, Smid HM: Olfactory coding in antennal neurons of the malaria mosquito, Anopheles gambiae. Chem Senses 2006, 31:845-863.

38. Carey AF, Wang GR, Su CY, Zwiebel $L$, Carlson JR: Odorant reception in the malaria mosquito, Anopheles gambiae. Nature 2010, 464:66-71.

39. Suer RA: Unravelling the Malaria Mosquito's Sense of Smell: Neural and Behavioural Responses to Human-Derived Compounds, PhD thesis. The Netherlands: Wageningen University; 2011.

40. Lin FM, Wilkens WF: Volatile flavor components of coconut meat. J Food Sci 1970, 35:538-539.

41. Mahajan SS, Goddik L, Qian MC: Aroma compounds in sweet whey powder. J Dairy Sci 2004, 87:4057-4063.

42. Smith DL, McKenzie FE, Snow RW, Hay Sl: Revisiting the basic reproductive number for malaria and its implications for malaria control. PLOS Biol 2007, 5:531-542

43. Kawada H, Temu EA, Minjas JN, Matsumoto O, Iwasaki T, Takagi M: Field evaluation of spatial repellency of metofluthrin-impregnated plastic strips against Anopheles gambiae complex in Bagamoyo, coastal Tanzania. J Am Mosa Control Assoc 2008, 24:404-409.

44. Ogoma SB, Ngonyani H, Simfukwe ET, Mseka A, Moore J, Killeen GF: Spatial repellency of transfluthrin-treated hessian strips against laboratory-reared Anopheles arabiensis mosquitoes in a semi-field tunnel cage. Parasit Vectors 2012, 5:54

45. Okumu FO, Govella NJ, Moore SJ, Chitnis N, Killeen GF: Potential benefits, limitations and target product-profiles of odor-baited mosquito traps for malaria control in Africa. PLoS One 2010, 5:e11573.

46. Mukabana WR, Mweresa CK, Omusula P, Orindi BO, Smallegange RC, van Loon JJA, Takken W: Evaluation of low density polyethylene and nylon for delivery of synthetic mosquito attractants. Parasit Vectors 2012, 5:202.

47. Reddy MR, Overgaard HJ, Abaga S, Reddy VP, Caccone A, Kiszewski AE, Slotman MA: Outdoor host seeking behaviour of Anopheles gambiae mosquitoes following initiation of malaria vector control on Bioko Island, Equatorial Guinea. Malar J 2011, 10:184.

48. Russell TL, Beebe NW, Cooper RD, Lobo NF, Burkot TR: Successful malaria elimination strategies require interventions that target changing vector behaviours. Malar J 2013, 12:56.

doi:10.1186/1475-2875-13-119

Cite this article as: Menger et al:: A push-pull system to reduce house entry of malaria mosquitoes. Malaria Journal 2014 13:119.

\section{Submit your next manuscript to BioMed Central and take full advantage of:}

- Convenient online submission

- Thorough peer review

- No space constraints or color figure charges

- Immediate publication on acceptance

- Inclusion in PubMed, CAS, Scopus and Google Scholar

- Research which is freely available for redistribution 